\title{
Psychosocial and Ergonomics Risk Factors Related to Neck, Shoulder and Back Complaints among Malaysia Office Workers
}

\author{
Norashikin Mahmud, Siti Fatimah Bahari, and Nurul Farha Zainudin
}

\begin{abstract}
Office workers are susceptible to physical health due to the nature of their work. It is therefore, the aim of this study to investigate the association between psychosocial and ergonomics risk factors and neck, shoulder and back complaints among office workers. A total number of 630 office workers participated in this study. The results showed that decision latitude was significantly correlated with shoulder [OR: $1.07(1.00-1.15)]$ and back [OR: $1.12(1.04-1.20)]$ complaints. The longer time spent sitting and keying were significantly correlated with neck [OR: $1.21(1.05-1.39)]$ and back [OR: $1.23(1.06-1.42)]$ [OR: $0.88(0.78-1.99)]$ complaints. Working overtime was also related with back complaints [OR: 1.43 (1.01 - 2.03)]. It is suggested that workers should schedule their break and stretching exercise in between tasks to prevent future overuse injury.
\end{abstract}

Index Terms-Musculoskeletal complaints, office workers, psychosocial factors, office ergonomics.

\section{INTRODUCTION}

There has been a tremendous increase in the use of computers in the workplace since the last decade. Office workers are among those who use computers to do their job daily. They spend many hours working with computers each day which make them vulnerable to work-related musculoskeletal disorders (MSDs) [1]. This is because they are exposed to office ergonomic risks such as prolong sitting in front of the computer, awkward posture and repetitive movement while typing and using mouse. It was reported in several studies that the intensive use of mouse and keyboard, uncomfortable work posture, remaining seated for prolonged periods, repetitive work and keyboard height were related to the development of MSDs [2]-[8]. Neck and shoulder pain is the most frequent reported MSDs [3], [9]-[11] among computer users in comparison to other disorders such as back, hand, elbow, and wrist [8], [12], [13].

Besides office ergonomic risk, psychosocial factors such as work demands, social support, job stress and work style may also contribute to work-related MSDs such as neck, shoulder, and upper limb [12], [14]-[17]. The combination of positive or negative effect of one or more psychosocial risk such as job demand, job insecurity, job control and support factors may potentially develop negative health related outcomes such as musculoskeletal complaints and psychological health [18].

In addition to the previous study, this study attempt to

Manuscript received August 14, 2013; revised October 15, 2013.

The authors are with the Faculty of Management, Universiti Teknologi Malaysia, Malaysia (e-mail: norashikin@management.utm.my). investigate the association between i) social support and decision latitude and neck, shoulder and back complaints, and ii) office ergonomic risk factors and neck, shoulder and back complaints among office workers.

\section{Methods}

\section{A. Participants}

The sample of this study consisted of office workers working in public sector. Questionnaire was distributed to the department/unit that has given their consent to participate in this study. Participation in this study is voluntary and they were given several days to fill in and return to the designated contact person.

\section{B. Measurement Tools}

The survey consisted of items covering psychosocial and office ergonomics risk factors and musculoskeletal complaints. Psychological risk factors refer to decision latitude and social support. The questionnaire was adopted from Karasek et al.[19]. Social support consisted of eight questions. While decision latitude consisted of six questions related to skill discretion and three questions related to decision authority. Respondents were to rate using 4 point Likert scales, ranging from strongly agree to strongly disagree. The office ergonomics risks factors were measured according to the number of years working using computer, number of hours keying and sitting in front of computer, number of times taking break, stretching exercise $(\mathrm{Y} / \mathrm{N})$, ability to alternate computer work and non-computer work $(\mathrm{Y} / \mathrm{N})$, regulate work pace $(\mathrm{Y} / \mathrm{N})$, experience time pressure to complete task $(\mathrm{Y} / \mathrm{N})$ and work overtime $(\mathrm{Y} / \mathrm{N})$.

Musculoskeletal complaints refer to any aches, pain, disorders or numbness in a body region as a result of computer work. Body regions of interest included the neck, shoulder and back (upper and lower). The right and left body regions were combined as one entity, for example left and right shoulder, as shoulder for analysis. The 12 month prevalence rate of MSDs was measured with the adapted Nordic Musculoskeletal Questionnaires (NMQ) [20]. The NMQ has been used extensively in different occupational settings to measure musculoskeletal disorders [21]-[24].

\section{Data Analysis}

The prevalence rates of musculoskeletal complaints were analyzed using frequencies and percentages with 95\% confidence intervals. Logistic regression analysis was used to assess the relationship between risk factors and musculoskeletal complaints among computer users. Gender, 
age and exercise were adjusted as confounder variables in the analysis.

\section{RESULTS}

The response rate was $63 \%$ (630 respondents). The majority of respondents were female $(72.1 \%)$. The average age of the respondents is $33.9 \pm 8.9$. The average years of working experience using computers is $10.6 \pm 6.8$.

\section{A. 12 Month Prevalence Rates of Musculoskeletal Complaints}

The findings of the study showed that the highest prevalence rates of musculoskeletal complaints among office workers is shoulder complaint $(51.4 \%)$, followed by neck $(49.4 \%)$ and back $(38.9 \%)$ (Table I).

TABLE I: PREVALENCE RATES OF NECK, SHOULDER AND BACK COMPLAINTS

\begin{tabular}{lcc}
\hline \multicolumn{1}{c}{ Body region } & Percentage (\%) & 95\% CI \\
\hline Neck & 49.4 & $45.5-53.3$ \\
Shoulder & 51.4 & $47.5-55.3$ \\
$\begin{array}{l}\text { Back (Upper and } \\
\text { lower) }\end{array}$ & 38.9 & $35.1-42.7$ \\
\hline
\end{tabular}

TABLE II: ASSOCIATION BETWEEN PSYCHOSOCIAL AND OFFICE ERGONOMICS RISK FACTORS AND NECK COMPLAINT ADJUSTED FOR GENDER, AGE AND EXERCISE

\begin{tabular}{lcc}
\hline & \multicolumn{2}{c}{ Neck } \\
\cline { 2 - 3 } & OR & $(\mathbf{9 5 \%} \mathbf{C I})$ \\
\hline Years working with & 1.00 & $(0.97-1.04)$ \\
computer & & \\
Hours Siting & $1.21 *$ & $(1.05-1.39)$ \\
Hours Keying & 0.91 & $(0.81-1.02)$ \\
Break & 0.99 & $(0.91-1.06)$ \\
Stretching & 1.08 & $(0.67-1.76)$ \\
Alternate Tasks & 1.14 & $(0.65-2.01)$ \\
Work Pace & 1.06 & $(0.66-1.69)$ \\
Time Pressure & 0.89 & $(0.58-1.39)$ \\
Overtime & 1.11 & $(0.79-1.56)$ \\
Decision latitude & 1.07 & $(1.00-1.14)$ \\
Social Support & 0.96 & $(0.92-1.01$ \\
\hline *Significant $p<0.05$ & &
\end{tabular}

\section{B. Association between Risk Factors and Musculoskeletal} Complaints

TABLE III: ASSOCIATION BETWEEN PSYCHOSOCIAL AND OFFICE ERGONOMICS RISK FACTORS AND SHOULDER COMPLAINT ADJUSTED FOR GENDER, AGE AND EXERCISE

\begin{tabular}{lcc}
\hline & \multicolumn{2}{c}{ Shoulder } \\
\cline { 2 - 3 } Risk factors & OR & $(\mathbf{9 5 \%} \mathbf{C I})$ \\
\hline Years working with & 1.03 & $(1.00-1.07)$ \\
computer & & \\
Hours Siting & 1.14 & $(0.99-1.32)$ \\
Hours Keying & 0.93 & $(0.83-1.05)$ \\
Break & 0.96 & $(0.89-1.04)$ \\
Stretching & 1.15 & $(0.70-1.88)$ \\
Alternate Tasks & 1.42 & $(0.80-2.50)$ \\
Work Pace & 0.84 & $(0.52-1.35)$ \\
Time Pressure & 1.17 & $(0.75-1.82)$ \\
Overtime & 1.24 & $(0.88-1.75)$ \\
Decision latitude & $1.07 *$ & $(1.00-1.15)$ \\
Social Support & 0.96 & $(0.91-1.01)$ \\
\hline *Significant $p<0.05$ & &
\end{tabular}

TABLE IV: ASSOCIATION BETWEEN PSYCHOSOCIAL AND OFFICE ERGONOMICS RISK FACTORS AND BACK COMPLAINT ADJUSTED FOR GENDER, AGE AND EXERCISE

\begin{tabular}{lcc}
\hline & \multicolumn{2}{c}{ Back } \\
\cline { 2 - 3 } & OR & $(\mathbf{9 5 \%}$ CI $)$ \\
\hline Years working with & 1.00 & $(0.95-1.03)$ \\
computer & & \\
Hours Siting & $1.23^{*}$ & $(1.06-1.42)$ \\
Hours Keying & $0.88^{*}$ & $(0.78-0.99)$ \\
Break & 1.00 & $(0.92-1.07)$ \\
Stretching & 1.17 & $(0.71-1.91)$ \\
Alternate Tasks & 1.20 & $(0.67-2.14)$ \\
Work Pace & 1.32 & $(0.82-2.15)$ \\
Time Pressure & 1.36 & $(0.87-2.10)$ \\
Overtime & $1.43 *$ & $(1.01-2.03)$ \\
Decision latitude & $1.12^{*}$ & $(1.04-1.20)$ \\
Social Support & 0.96 & $(0.91-1.01)$ \\
\hline *Significant $p<0.05$ & &
\end{tabular}

The results of the analysis indicated that only number of hours sitting is significantly associated with neck compliant $(p=0.01)$ (Table II). As for the shoulder complaint, decision latitude was significantly correlated with the complaint ( $p=$ 0.04) (Table III). The findings showed that the number of hours sitting ( $p=0.006)$, number of hours keying ( $p=0.031)$, working overtime ( $p=0.043)$ and decision latitude $(p=0.002)$ were correlated with back complaints among computer users (Table IV).

\section{DISCUSSION}

The findings of this study reported high prevalence rates of neck, shoulder and back complaints among office workers. These findings are consistent with other studies conducted among computer users in Malaysia. One study reported 33\% (95\% CI 28.8 to 37.3) prevalence of work-related upper limb disorder (WRULS) and those who used computers more than 5 hours per day are 7.5 times (95\% CI 2.3 to 24.2) more likely of developing WRULS [25]. Another study conducted by Sen et al. [26] related to the symptoms of Occupational Overuse Syndrome (OOS) among 136 secretarial staff and undergraduate students who used computer. The study reported that non proper workstation ergonomics increased the risk of developing neck, back and wrist disorders. In addition, the findings from the western counterparts also reported high prevalence rates of musculoskeletal complaints among computer users; from example in the Netherlands [3], Sweden [9], [27], Brazil [28], Germany [4], Finland [11], Australia [29] and US [30].

Time spent sitting in front of the computer was the significant risk factor for neck and back complaints. While longer hours spent typing was found to be a risk factor for back complaints. These findings are supported by several other studies on the effect of ergonomic factors such as longer hours of mouse and keyboard use, prolonged sitting and uncomfortable postures in workers on MSDs [8], [11], [28], [31].

Working overtime is also significantly correlated with back complaints. Working overtime means workers have to work beyond one's scheduled working hours. Workers might need to finish their work deadline and facing with heavy job demands. Our finding is in consistent with study conducted 
by de Castro [32], reported that frequency of working mandatory overtime was associated with work-related injury. Further, it was reported in another study that working in jobs with overtime schedules put workers at higher injury hazard rate compare to jobs without overtime [33]. Our study also found that decision latitude was the risk factor for shoulder and back complaints among computer users. The result is in accordance with the findings of a systematic review suggested that there is association between psychosocial risk factors such as job demands, social support, decision latitude and upper extremity disorders [34] .

It can be concur from our findings and other previous studies that office workers are susceptible to musculoskeletal complaints and can be incremental if they were not prevented at the early stage. This can be supported by the findings from the prospective longitudinal studies ranging from three months to 5.4 years, the risk of disorders increases among those who have high work strain, intensive mouse and keyboard use, perceived high muscle tension and previous neck and shoulder symptoms [5], [7], [15], [29], [35]-[37] in a long run.

\section{CONCLUSION}

There was as high prevalence rates of musculoskeletal complaints in the neck, shoulder and back. Number of hours spent sitting and typing, working overtime and decision latitude were related to neck, shoulder and back complaints among office workers. It was suggested that workers should schedule their break and stretching exercise in between task to avoid overuse injury. Employers should provide employees with flexible work station and training on office ergonomics to provide them with appropriate knowledge.

\section{REFERENCES}

[1] A. E. Dembe, "The changing nature of office work: Effects on repetitive strain injuries," Occup Med, vol. 14, no. 1, pp. 61-72, 1999.

[2] B. Demure, R. S. Luippold, C. Bigelow et al., "Video display terminal workstation improvement program: I. Baseline associations between musculoskeletal discomfort and ergonomic features of workstations," Journal of Occupational and Environmental Medicine, vol. 42, no. 8, pp. 783-91, 2000.

[3] S. Eltayeb, J. B. Staal, J. Kennes et al., "Prevalence of complaints of arm, neck and shoulder among computer office workers and psychometric evaluation of a risk factor questionnaire," $B M C$ Musculoskeletal Disorders, vol. 8, pp. 68, 2007.

[4] A. Klussmann, H. Gebhardt, F. Liebers et al., "Musculoskeletal symptoms of the upper extremities and the neck: A cross-sectional study on prevalence and symptom-predicting factors at visual display terminal (vdt) workstations," BMC Musculoskeletal Disorders, vol. 9, pp. 96, 2008.

[5] A. I. Kryger, J. H. Andersen, C. F. Lassen et al., "Does computer use pose an occupational hazard for forearm pain; from the nudata study," Occupational and Environmental Medicine, vol. 60, no. 11, pp. 14, 2003.

[6] M. Marcus and F. Gerr, "Upper extremity musculoskeletal symptoms among female office workers: Associations with video display terminal use and occupational psychosocial stressors," American Journal of Industrial Medicine, vol. 29, no. 2, pp. 161-70, 1996.

[7] R. A. Nicholas, M. Feuerstein, and S. Suchday, "Workstyle and upper-extremity symptoms: A biobehavioral perspective," Journal of Occupational and Environmental Medicine, vol. 47, no. 4, pp. 352-61, 2005.

[8] L. O. Hernandez, S. T. Gonzalez, S. M. Alcantara et al., "Computer use increases the risk of musculoskeletal disorders among newspaper office workers," Archives of Medical Research, vol. 34, no. 4, pp. 331-42, Jul.-Aug. 2003.

[9] J. Hanse, "The impact of vdu use and psychosocial factors at work on musculoskeletal shoulder symptoms among white-collar workers," Work and Stress, vol. 16, no. 2, pp. 121-26, 2002.

[10] V. Johnston, T. Souvlis, N. L. Jimmieson et al., "Associations between individual and workplace risk factors for self-reported neck pain and disability among female office workers," Applied Ergonomics, vol. 39, no. 2, pp. 171-82, Mar. 2008

[11] T. Korhonen, R. Ketola, R. Toivonen et al., "Work related and individual predictors for incident neck pain among office employees working with video display units," Occupational and Environmental Medicine, vol. 60, no. 7, pp. 475-82, 2003.

[12] A. Leroyer, J. Edmé, X. Vaxevanoglou et al., "Neck, shoulder, and hand and wrist pain among administrative employees: Relation to work-time organization and psychosocial factors at work," Journal of Occupational and Environmental Medicine, vol. 48, no. 3, pp. 326-33, 2006.

[13] P. Spyropoulos, G. Papathanasiou, G. Georgoudis et al., "Prevalence of low back pain in greek public office workers," Pain Physician, vol. 10, no. 5, pp. 651-60, 2007.

[14] J. B. Lanfranchi and A. Duveau, "Explicative models of musculoskeletal disorders (msd): From biomechanical and psychosocial factors to clinical analysis of ergonomics," European Review of Applied Psychology, vol. 58, no. 4, pp. 201-13, 2008.

[15] L. M. Hannan, C. P. Monteilh, F. Gerr et al., "Job strain and risk of musculoskeletal symptoms among a prospective cohort of occupational computer users," Scandinavian Journal of Work, Environment \& Health, vol. 31, no. 5, pp. 375-86, 2005.

[16] A. J. Haufler, M. Feuerstein, and G. D. Huang, "Job stress, upper extremity pain and functional limitations in symptomatic computer users," American Journal of Industrial Medicine, vol. 38, no. 5, pp. 507-15, Nov. 2000.

[17] M. F. Polanyi, D. C. Cole, D. E. Beaton et al., "Upper limb work-related musculoskeletal disorders among newspaper employees: Cross-sectional survey results," American Journal of Industrial Medicine, vol. 32, no. 6, pp. 620-8, Dec. 1997.

[18] G. D. Huang, M. Feuerstein, and S. L. Sauter, "Occupational stress and work-related upper extremity disorders: Concepts and models," American Journal of Industrial Medicine, vol. 41, no. 5, pp. 298-314, 2002.

[19] R. Karasek, C. Brisson, N. Kawakami et al., "The job content questionnaire (jcq): An instrument for internationally comparative assessments of psychosocial job characteristics," Journal of Occupational Health Psychology, vol. 3, no. 4, pp. 322-55, Oct. 1998.

[20] I. Kuorinka, B. Jonsson, A. Kilbom et al., "Standardised nordic questionnaires for the analysis of musculoskeletal symptoms," Applied Ergonomics, vol. 18, no. 3, pp. 233-37, 1987.

[21] A. Alipour, M. Ghaffari, B. Shariati et al., "Occupational neck and shoulder pain among automobile manufacturing workers in Iran," American Journal of Industrial Medicine, vol. 51, no. 5, pp. 372-9, May 2008.

[22] A. Choobineh, S. H. Tabatabaei, A. Mokhtarzadeh et al., "Musculoskeletal problems among workers of an iranian rubber factory," Journal of Occupational Health, vol. 49, no. 5, pp. 418-23, Sep. 2007.

[23] M. Malinska and J. Bugajska, "The influence of occupational and non-occupational factors on the prevalence of musculoskeletal complaints in users of portable computers," International Journal of Occupational Safety and Ergonomics, vol. 16, no. 3, pp. 337-43, 2010.

[24] D. Picoloto and E. da Silveira, "Prevalence of musculoskeletal symptoms and associated factors among metal industry workers in canoas," Ciencia and Saude Coletiva, vol. 13, no. 2, pp. 507-16, Mar.-Apr. 2008.

[25] Z. A. Rahman, "Prevalence of work-related upper limbs symptoms (wruls) among office workers," Asia-Pacific Journal of Public Health, vol. 21, no. 3, pp. 252-58, 2009.

[26] A. Sen and S. Richardson, "A study of computer-related upper limb discomfort and computer vision syndrome," Journal of Human Ergology, vol. 36, no. 2, pp. 45-50, Dec 2007.

[27] J. Wahlstrom, A. Lindegard, and G. Ahlborg et al., "Perceived muscular tension, emotional stress, psychological demands and physical load during vdu work," International Archives of Occupational and Environmental Health, vol. 76, no. 8, pp. 584-90, 2003.

[28] L. E. Rocha, D. M. Glina, M. F. Marinho et al., "Risk factors for musculoskeletal symptoms among call center operators of a bank in são paulo, brazil," Industrial Health, vol. 43, no. 4, pp. 637-46, 2005. 
[29] J. M. Hush, Z. Michaleff, C. G. Maher et al., "Individual, physical and psychological risk factors for neck pain in australian office workers: A 1-year longitudinal study," European Spine Journal, vol. 18, no. 10, pp. 1532-40, 2009.

[30] L. Smith, Q. Louw, L. Crous et al., "Prevalence of neck pain and headaches: Impact of computer use and other associative factors," Cephalalgia, vol. 29, no. 2, pp. 250-7, Feb 2009.

[31] K. T. Palmer, C. Cooper, K. Walker-Bone et al., "Use of keyboards and symptoms in the neck and arm: Evidence from a national survey," Occupational Medicine, vol. 51, no. 6, pp. 392-5, Sep 2001.

[32] A. B. de Castro, A. B. Fujishiro, K. T. Rue, E. A. Tagalog, L. P. G. Samaco-Paquiz, and G. C. Gee, "Associations between work schedule characteristics and occupational injury and illness," International Nursing Review, vol. 57, no. 2, pp. 188-94, 2010.

[33] A. S. Dembe, J. B. Erickson, R. G. Delbos et al., "The impact of overtime and long work hours on occupational injuries and illnesses: New evidence from the united states," Occupational Environment Medicine, vol. 62, pp. 588-97, 2005.

[34] P. Bongers, A. Kremer, and J. ter Laak, “Are psychosocial factors'risk factors for symptoms and signs of the shoulder, elbow or hand/wrist? A review of the epidemiological literature," Am J Ind Med, vol. 41, no. 5, pp. 315-42, 2002.

[35] L. P. Brandt, J. H. Andersen, C. F. Lassen et al., "Neck and shoulder symptoms and disorders among danish computer workers," Scandinavian Journal of Work, Environment \& Health, vol. 30, no. 5, pp. 399-409, 2004.

[36] B. J. Kristensen, K. Sogaard, J. Stroyer et al., "Computer users' risk factors for developing shoulder, elbow and back symptoms," Scandinavian Journal of Work, Environment \& Health, vol. 30, no. 5 , pp. 390-8, Oct 2004.

[37] R. A. Werner, A. Franzblau, N. Gell et al., "Predictors of upper extremity discomfort: A longitudinal study of industrial and clerical workers," Journal of Occupational Rehabilitation, vol. 15, no. 1, pp. $27-35,2005$.

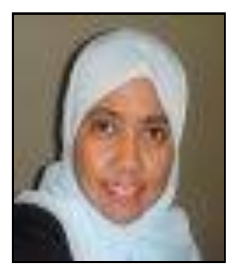

Norashikin Mahmud is a senior lecturer at the Faculty of Management, Universiti Teknologi Malaysia, Johor Bahru Campus. She obtained her Phd in Health Sciences from University of Sydney, Australia in 2011. She is with UTM for more than 12 years and currently active in research related to occupational health and safety and industrial and organizational Psychology. (Tel: +6075557799; Fax: +607-5610099, e-mail: norashikin@management.utm.my)

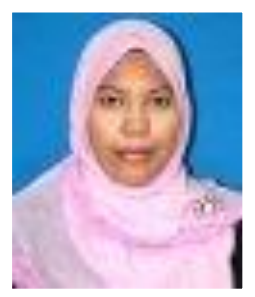

Siti Fatimah Bahari is a senior lecturer at the Department of Human Resource Development (Program of Psychology), Faculty of Management, Universiti Teknologi Malaysia, Johor Bahru Campus. She obtained her Phd in Organizational Psychology from University of Manchester, United Kingdom in 2011. She is with UTM for more than 13 years and currently active in research related to Safety and Health Management, Safety Training, Safety Culture/Climate, Organizational \& Industrial Psychology, and Social Science. (Tel: +6075510066), Fax: +607-5610099, email: sitifatimah@management.utm.my).

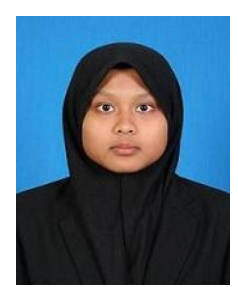

Nurul Farha Zainuddin is a master student in Science (Human Resource Development) at the Faculty of Management, Universiti Teknologi Malaysia. She obtained her Degree in Sport Science from Universiti Teknologi MARA at the Faculty of Sport Science and Recreation. (Tel: +60167629203; email: nurulfarha26@gmail.com) 